\title{
Mechanism of Allopurinol-Mediated Increase in Enzyme Activity in Man
}

\author{
Thomas D. Beardmore, Jay S. Cashman, and William N. Kelley \\ From the Division of Rheumatic and Genetic Diseases, Department of \\ Medicine, Duke University Medical Center, \\ Durham, North Carolina 27710
}

\begin{abstract}
A B S T R A C T Allopurinol therapy in man interferes with pyrimidine biosynthesis de novo by inhibition of one or both of the two enzymes, orotate phosphoribosyltransferase (OPRT) and orotidylic decarboxylase (ODC), responsible for the conversion of orotic acid to uridine-5'-monophosphate. Inhibition of this pathway in vivo is followed in 1-3 wk by an increase in the activity of both of these enzymes in erythrocytes and of ODC in circulating leukocytes. This drug-mediated increase in enzyme activity in erythrocytes could not be attributed to enzyme stabilization or induction in vivo but appeared to be due to enzyme "activation." "Activation" of the OPRT enzyme was directly demonstrated in erythrocytes studied in vitro after incubation with oxipurinol, and to a lesser extent, with allopurinol. No evidence for "activation" of the ODC enzyme was demonstrated in vitro. This response to allopurinol therapy provides an excellent model for examining the mechanism of increased enzyme activity in response to drug administration.
\end{abstract}

\section{INTRODUCTION}

Allopurinol (4-hydroxypyrazolo-(3,4-d)-pyrimidine) is widely used as a hypouricemic agent in man. This compound, which is an analogue of hypoxanthine, serves as both a substrate and an inhibitor of xanthine oxidase the enzyme which catalyzes the oxidation of hypoxanthine to xanthine and xanthine to uric acid (1-3). Allopurinol itself is rapidly oxidized in vivo by xanthine oxidase to oxipurinol (4,6-dihydroxypyrazolo-(3,4-d)-pyrimidine), an analogue of xanthine, which is also an inhibitor of xanthine oxidase. However, unlike allopurinol, oxipurinol has a long half-life in vivo (1-3).

Received for publication 7 October 1971 and in revised form 25 February 1972.
In addition to their inhibitory effect on purine catabolism, both allopurinol and oxipurinol have been shown to have striking effects on pyrimidine metabolism. The administration of either compound leads to an increase in the urinary excretion of orotic acid and orotidine $(4,5)$; this effect has been attributed to inhibition of pyrimidine biosynthesis de novo at one or both of the two enzymes, orotate phosphoribosyltransferase (OP$\mathrm{RT})^{1}$ and orotidylic decarboxylase (ODC), involved in the conversion of orotic acid to uridine- $5^{\prime}$-monophosphate (UMP) (Fig. 1) (4-6). In addition, the activity of the former enzyme, OPRT, which catalyzes the formation of orotidine- 5 -monophosphate (OMP) from orotic acid, has been found to be increased in erythrocytes from allopurinol-treated patients (4).

The observation that drug-mediated inhibition of pyrimidine biosynthesis is associated with increased activity of enzymes in this pathway provided a possible biochemical model of drug tolerance in man. In the present study, we have documented an increase in activity of both OPRT and ODC in circulating erythrocytes obtained from patients receiving allopurinol. In addition, we have examined the mechanism responsible for this increase in enzyme activity as well as the relationship of this change to the development of tolerance.

\section{METHODS}

Orotic acid-6- ${ }^{14} \mathrm{C}(43.5 \mathrm{mCi} / \mathrm{mmole})$, orotic acid-7- ${ }^{14} \mathrm{C}(8.3$ $\mathrm{mCi} / \mathrm{mmole})$, orotidine- $5^{\prime}$-monophosphate-7- ${ }^{14} \mathrm{C}(21 \mathrm{mCi} /$ mmole $)$, adenine- $8-{ }^{14} \mathrm{C}(27.2 \mathrm{mCi} / \mathrm{mmole})$, and guanine-8- ${ }^{14} \mathrm{C}$ ( $31.6 \mathrm{mCi} / \mathrm{mmole})$ were obtained from New England Nuclear

\footnotetext{
${ }^{1}$ Abbreviations used in this paper: APRT, adenine phosphoribosyltransferase; HGPRT, hypoxanthine-guanine phosphoribosyltransferase; ODC, orotidylic decarboxylase; OMP, orotidine-5'-monophosphate; OPRT, orotate phosphoribosyltransferase; PBS, phosphate-buffered saline; PP-ribose-P, phosphoribosylpyrophosphate; UMP, uridine-5'-monophosphate.
} 


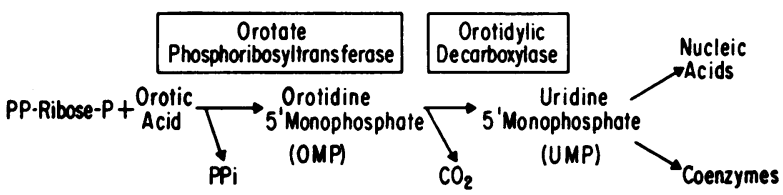

Figure 1 The reactions involved in the conversion of orotic acid to uridine- 5 '-monophosphate which are catalyzed by orotate phosphoribosyltransferase and orotidylic decarboxylase.

Corp., Boston, Mass. Phosphoribosylpyrophosphate (PPribose-P) and 6-azauridylic acid were obtained from Calbiochem, Inc., Los Angeles, Calif. Dibutyl phthalate (specific gravity 1.046) and dimethyl phthalate (specific gravity 1.191) were purchased from Eastman Kodak Co., Rochester, N. Y. Allopurinol and oxipurinol were gifts from Dr. Gertrude B. Elion, Burroughs Wellcome \& Co., Research Triangle Park, N. C. All other chemicals and reagents used were of the highest quality commercially available.

OPRT was assayed by a microradiochemical method described previously in which the conversion of orotic acid-6${ }^{14} \mathrm{C}$ to OMP-6- ${ }^{14} \mathrm{C}$ is determined in the presence of 6 -azauridylic acid, PP-ribose- $\mathrm{P}$, and magnesium (7). Using this assay the formation of OMP was linear with respect to time and protein concentration and under all conditions less than $6 \%$ of the labeled OMP was converted to UMP. The Michaelis constants observed for orotate and PP-ribose-P were comparable to values obtained for the purified OPRT enzyme obtained from other mammalian sources (8). ODC was assayed by following the liberation of ${ }^{14} \mathrm{CO}_{2}$ from OMP-7- ${ }^{14} \mathrm{C}$ as described previously (5). Hypoxanthineguanine phosphoribosyltransferase (HGPRT) and adenine phosphoribosyltransferase (APRT) were assayed by the method of Kelley, Rosenbloom, Henderson, and Seegmiller (9). Each of these enzymes were found to be relatively stable in undiluted, undialyzed hemolysates for at least $2 \mathrm{wh}$ when stored at $-70^{\circ}$ providing the samples were not repeatedly thawed and frozen. However, in order to further insure stability of these enzymes in hemolysate which were to be stored for more than a few hours, most samples were stored in the presence of $5 \mathrm{~mm} \mathrm{Mg}^{++}$and $1 \mathrm{~mm}$ PP-ribose-P. Protein was determined by the method of Lowry (10) and serum urate by an enzymatic method (11). Urinary oxypurines were determined by enzymatic conversion to uric acid (12). Urinary pyrimidines were identified and quantitated with the UV analyzer which was developed by the Biological Fluids Division of the Oak Ridge National Laboratory (13).

TABLE I

The Effect of Allopurinol Therapy on Orotate Phosphoribosyltransferase (OPRT) and Orotidylic Decarboxylase (ODC) Activity in Circulating Erythrocytes in Man

\begin{tabular}{llc}
\hline & $\begin{array}{c}\text { OPRT } \\
\text { (mean } \pm \mathrm{SD})\end{array}$ & $\begin{array}{c}\text { ODC } \\
(\text { mean } \pm \mathrm{SD})\end{array}$ \\
\hline & nmoles $/ m g$ protein $/ h r$ & nmoles $/$ mg protein $/ h r$ \\
Control & $0.121 \pm 0.064(29)$ & $0.128 \pm 0.068(37)$ \\
Allopurinol & $1.057 \pm 0.426^{*}(13)$ & $1.045 \pm 0.406^{*}(16)$
\end{tabular}

Number of patients indicated in parentheses.

* $P$ value (Student $t$ test) $<0.001$.
The effect of initiation of allopurinol or oxipurinol therapy on enzyme activity in circulating erythrocytes was determined in nine patients with gout. Seven of these gouty subjects (R. R., J. M., C. R., W. H. H., A. B., P. S., and J. W.) were hospitalized on the Clinical Research Unit where they were maintained on a diet essentially free of purines and controlled drug regimen for at least 3 days before and during the study period. Two patients (A. H. and J. E. J.) were scudied as outpatients where drug intake was less rigorously controlled and no attempt was made to control the diet. All nine patients had either never been treated with allopurinol or had been requested to discontinue the drug 1 month before the study. In three of the hospitalized fatients who had not previously been treated with allopurinol, the effect of allopurinol (J. M. and C. R.) or oxipurinol (W. H. H.) on enzyme aciivity was determined in erythrocytes separated by their density.

The metabolism of orotic acid $7{ }^{14} \mathrm{C}$ in vivo was determined in three of these gouty patients (A. B., P. S., and J. W.) before and during allopurinol therapy by following the excretion of ${ }^{14} \mathrm{C}$-metabolites of orotic acid in the urine and of ${ }^{14} \mathrm{CO}_{2}$ in expired air (14). Orotic acid-7- ${ }^{14} \mathrm{C}$ was dissolved in physiologic saline, sterilized by filtration through a $0.2 \mu$ Millipore filter (Millipore Corp., Bedford, Mass.) and administered i.v. at a dosage of $0.15 \mu \mathrm{Ci} / \mathrm{kg}$. After administration of orotic acid- $7-{ }^{14} \mathrm{C}$, all urine was collected at 30-min intervals for $2 \frac{1}{2} \mathrm{hr}$ and then every $6 \mathrm{hr}$ for $48 \mathrm{hr}$. Expired air was collected for $3 \mathrm{~min}$ every $7-15 \mathrm{~min}$ in meterologic balloons for the first $2 \frac{1}{2} \mathrm{hr}$ (total of 11 samples). Portions (100-200 $\mu 1)$ from each urine sample were suspended in Bray's solution and counted in a Packard Tricarb scintillation spectrometer (Packard Instrument Co., Inc., Downers Grove, Ill.) using external standardization.

For at least the first $2 \frac{1}{2} \mathrm{hr}$, approximately $90 \%$ of the ${ }^{11} \mathrm{C}$ detectable in the urire was present as orotic acid- ${ }^{14} \mathrm{C}$ after separation by descending paper chromatography in butanol: acetic acid: water $(2: 1: 1)$. Measured portions of expired air (usually $3000 \mathrm{ml}$ ) were bubbled through two $5 \mathrm{ml}$ volumes of methanol-ethanolamine $(80: 20)$ solution. A portion of this methanol-ethanolamine solution was then suspended in a triton-toluene scintillation fluid and counted in a Packard Tricarb Scintillation spectrometer at $82 \%$ efficiency (15). The efficiency of the ethanolamine-methanol system for trapping ${ }^{14} \mathrm{CO}_{2}$ was greater than $95 \%$. The $\mathrm{P}_{\mathrm{CO}_{2}}$ of each portion of expired air was determined by a gas electrode in order to correct for variation in ventilation and to calculate the total $\mathrm{CO}_{2}$ in expired air using the gas law. Urinary ${ }^{14} \mathrm{C}$ metabolites are expressed as dpm excreted per total urine volume for the $48 \mathrm{hr}$ period. The excretion of ${ }^{14} \mathrm{CO}_{3}$ in expired air is expressed as $\mathrm{dpm} / \mathrm{mmole} \mathrm{CO}_{2}$ per tctal measured volume and represents the total radioactivity recovered in the 11 portions collected during the $2 \frac{1}{2} \mathrm{hr}$ test period.

Leukocytes were separated from erythrocytes by selective osmotic lysis of erythrocytes according to the method of Chodirker, Bock, and Vaughan (16) or by differential sedimentation of erythrocytes in the presence of fibrinogen (17). Although all the data presented in the present study was obtained using the former method, the latter method usually provided a better separation of leukocytes from erythrocytes and accordingly leukocyte ODC activity generally appeared somewhat higher using this technique. Cell suspensions were prepared by determining the total wet weight and adding sufficient volume of $0.05 \mathrm{M} \mathrm{Na}$ phosphate buffer, $\mathrm{pH} 7.4$ to achieve a concentration of $80-100 \mathrm{mg} / \mathrm{ml}$. The cells were lysed by rapidly freezing and thawing twice in dry ice and 

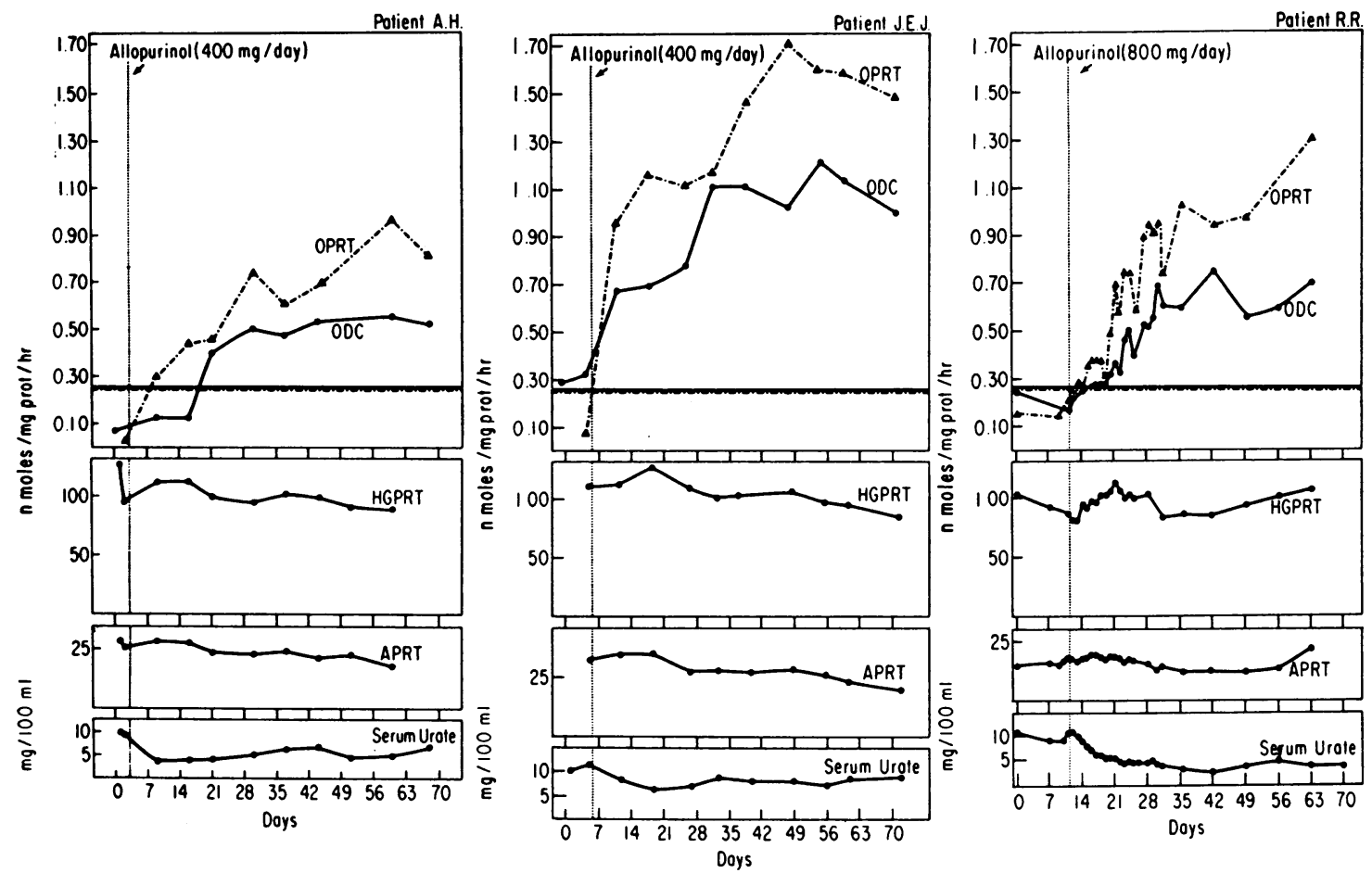

FIGURE 2 The effect of allopurinol therapy on erythrocyte orotidylic decarboxylase (ODC), orotate phosphoribosyltransferase (OPRT), hypoxanthine-guanine phosphoribosyltransferase (HGPRT), and adenine phosphoribosyltransferase (APRT), and serum urate in three patients with gout. The upper limits of normal OPRT and ODC activity in erythrocytes (mean $+2 \mathrm{SD})$ are indicated by the dotted and solid horizontal lines, respectively.

acetone. After centrifugation at $2500 \mathrm{~g}$ for $30 \mathrm{~min}$, the supernatant was withdrawn for enzyme analysis.

Erythrocytes were separated by their specific density using a modification of the method of Brok, Ramot, Zwang, and Danon (18). $25 \mathrm{ml}$ of freshly drawn heparinized venous blood was divided into two equal volumes. Each of these samples were overlaid with $2 \mathrm{ml}$ of dimethyl-dibutyl phthalate mixture with a specific gravity of 1.090 (prepared by mixing appropriate volumes of dimethyl and dibutyl phthalate solution) and centrifuged for $90 \mathrm{~min}$ at $12,000 \mathrm{~g}$ at $15^{\circ} \mathrm{C}$. After centrifugation, the buffy coat and plasma were withdrawn and discarded. Each of the two red cell fractions (separated by the nonmiscible phthalate solution) was transferred to another Nalgene or glass tube. The upper volume was overlaid with $1 \mathrm{ml}$ phthalate mixture with a specific gravity of 1.086 and the lower was overlaid with $1 \mathrm{ml}$ phthalate mixture with a specific gravity of 1.094 . The cells were centrifuged for $90 \mathrm{~min}$ at $12,000 \mathrm{~g}$ and $15^{\circ} \mathrm{C}$. This two-stage centrifugation resulted in four red cell samples of approximately equal volume with four specific densities: (a) less than 1.086 ; $(b)$ greater than 1.086 but less than 1.090 ; (c) greater than 1.090 but less than 1.094 ; and (d) greater than 1.094. The least dense cells correspond to the youngest and the most dense to the oldest cells (19). Using this method to fractionate erythrocytes from a patient 3 days after administration of ${ }^{50} \mathrm{Fe}$ we found less than $9 \%$ contamination of the three most dense cell fractions by the relatively young cells which would have been labeled by the recent administration of radioactive $\mathrm{Fe}$. The cells obtained by phthalate fractionation were washed with normal saline, lysed by repeated freezing and thawing, and dialyzed for $2 \mathrm{hr}$ against $0.05 \mathrm{M} \mathrm{Na}$ phosphate buffer, $\mathrm{pH}$ 7.40. Enzyme activity for the four fractions was determined as described above and specific activity was expressed as nanomoles per milligram protein per hour and as per cent of the mean of the four fractions.

Erythrocytes for in vitro studies were separated from plasma by centrifugation immediately after venopuncture, washed with 4 vol of phosphate-buffered saline (PBS), $\mathrm{pH} 7.40$, and resuspended in PBS at $20 \%$ red cell concentration. This suspension was incubated with constant shaking at $37^{\circ} \mathrm{C}$ for up to $4 \mathrm{hr}$ in the presence and absence of oxipurinol or allopurinol. The cells were then washed with PBS, lysed by rapid freezing and thawing, dialyzed for $2 \mathrm{hr}$ against $0.01 \mathrm{M}$ Tris $\mathrm{HCl}, \mathrm{pH} 7.40$, and assayed for OPRT and ODC activity.

Statistical significance of data was determined where indicated by the Student $t$ test, line regression analysis by least squares for coincident and parallel lines, and multivariate analysis of variance using a Xerox Sigma 5 computer (20).

\section{RESULTS}

Effect of allopurinol on OPRT and ODC in circulating erythrocytes. A single heparinized blood sample was obtained for enzyme assay from 37 patients (including normal and gouty patients) who were not receiving allopurinol and from 16 patients with gout who had received $400-800 \mathrm{mg}$ of allopurinol daily for $2 \mathrm{wk}$ 

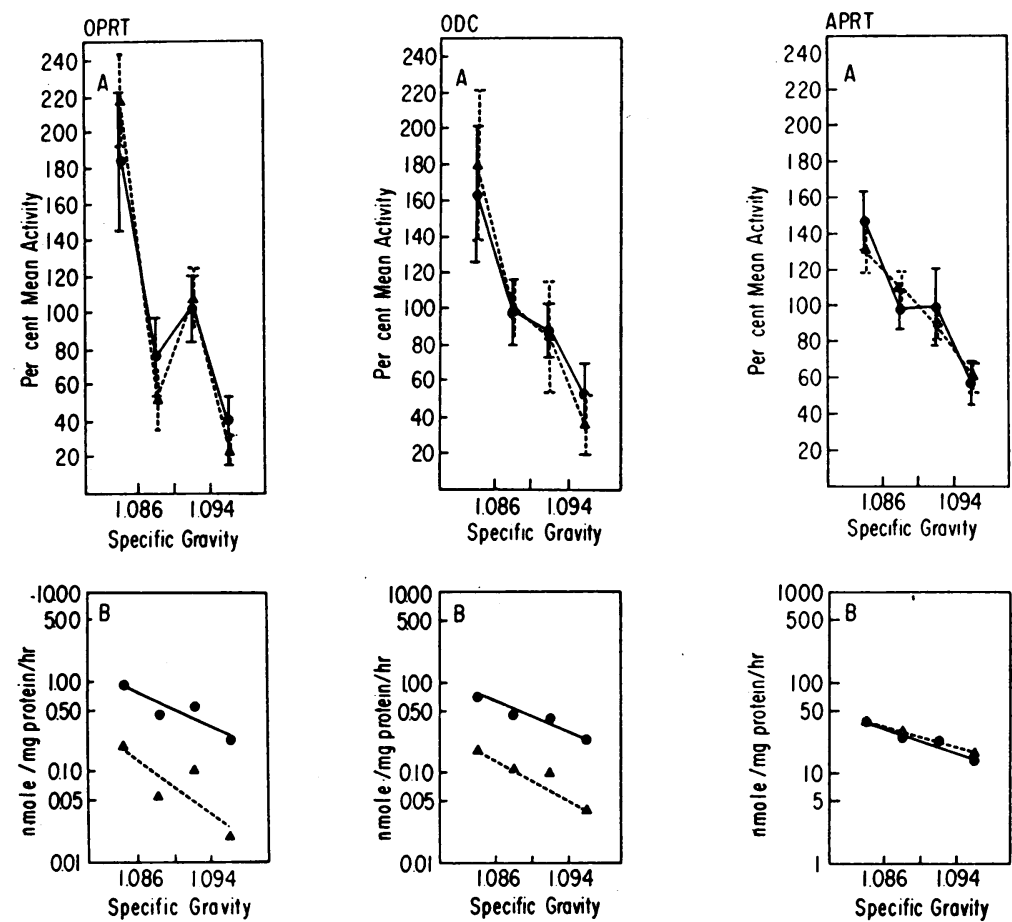

FIGURE 3 The activity of adenine phosphoribosyltransferase (APRT), orotidylic decarboxylase (ODC), and orotate phosphoribosyltransferase (OPRT) in erythrocytes of different density. (A) Activity in each fraction expressed as per cent of mean activity $( \pm S D)$ and plotted on arithmetic scale. (B) Mean specific activity in each fraction plotted on logarithmic scale. Allopurinol therapy

to 6 yr. Erythrocyte OPRT and ODC activities were found to be 8.7 - and 8.2 -fold higher, respectively, in the allopurinol-treated group when compared with the control group (Table I). These data confirm in a larger group of patients the elevated erythrocyte OPRT activity recently reported by Fox, Royse-Smith, and O'Sullivan (4) and demonstrate a similar increase in erythrocyte ODC activity.

The specific activities of OPRT, ODC, and two purine phosphoribosyltransferase enzymes, HGPRT and APRT, in circulating erythrocytes obtained from three patients before and during $10 \mathrm{wk}$ of allopurinol therapy are illustrated in Fig. 2. The erythrocyte ODC and

TABLE II

The Effect of Allopurinol Therapy on Orotidylic Decarboxylase $(O D C)$ in Circulating Leukocytes

\begin{tabular}{lcc}
\hline & No. & $\begin{array}{c}\text { ODC activity } \\
\text { (mean } \pm \text { SD) }\end{array}$ \\
\hline & 15 & $n$ moles $/ m g$ protein/hr \\
Control & $15.38 \pm 1.57$ \\
Allopurinol $(300-800 \mathrm{mg} /$ day) & 10 & $5.74 \pm 1.61$ \\
\hline
\end{tabular}

OPRT activity began to increase from 3 to 7 days after initiation of allopurinol therapy and reached a relatively stable level in 3-6 wk. In each of these three patients, the increase in OPRT activity was greater and appeared to occur sooner than the increase in ODC activity. However, in several patients treated with prolonged therapy the final levels of activity of OPRT and ODC observed in erythrocytes in vivo were similar (see Tables I and III). There was no significant change in the activity of the two purine phosphoribosyltransferase enzymes, HGPRT and APRT.

Effect of allopurinol on $O D C$ activity in circulating leukocytes. ODC was assayed in leukocytes from 15 normal untreated patients and 10 gouty patients receiving allopurinol at a dose ranging from 300 to 800 $\mathrm{mg}$ /day (Table II). In leukocytes as in erythrocytes ODC activity was significantly higher $(P<0.025)$ in allopurinol treated patients when compared to untreated patients. However, the magnitude of the increase in ODC activity in leukocytes was substantially less than that observed in erythrocytes. Similar increases in leukocyte ODC activity were seen in one patient treated with oxipurinol.This effect of allopurinol or oxipurinol 
on ODC activity in leukocytes was maximal as early as 3 days after initiation of therapy.

Effect of prolonged allopurinol therapy on the metabolism of orotic acid-7. ${ }^{14} C$ in vivo. The metabolism of orotic acid-7- ${ }^{14} \mathrm{C}$ in three gouty patients before and after allopurinol therapy is illustrated in Table III. Patients A. B., P. S., and J. W. had increased urinary excretion of ${ }^{14} \mathrm{C}$ metabolites of orotic acid and decreased excretion of ${ }^{14} \mathrm{CO}_{3}$ in expired gas after initiation of therapy, and both of these effects were essentially unchanged after 60 days therapy. Erythrocyte OPRT and ODC activities increased 8-10-fold during this treatment period. When allopurinol was discontinued for 7 days patients A. B. and P. S. had an increased excretion of ${ }^{14} \mathrm{CO}_{2}$ in expired air. The effect was more marked in patient P. S., who excreted $33 \%$ more labeled $\mathrm{CO}_{2}$ than during the control pretherapy period. Urinary excretion of ${ }^{14} \mathrm{C}$ metabolites returned essentially to basal levels with cessation of therapy in these two patients.

Effect of prolonged allopurinol therapy on the urinary excretion of orotidine and orotic acid. Urinary orotic acid and orotidine were quantitated serially in three gouty patients (R. R., A. H., and J. E. J.) receiving allopurinol at a dose of $400-800 \mathrm{mg} /$ day for up to 120 days. In the former subject the values reported are based on 24-hr collection periods whereas in the latter two subjects early morning urine samples were obtained and the values reported are based on a creatinine excretion of $2.5 \mathrm{~g} /$ day which is approximately the daily creatinine excretion in these two subjects. The effect of allopurinol therapy on urinary excretion of orotidine and orotic acid as well as uric acid and oxypurines in these three patients is illustrated in Table IV. There was no consistent decrease in the urinary excretion of either orotidine or orotic acid in the three patients over a 10-17 wk period despite the striking increases in erythrocyte OPRT and ODC activity.

Effect of allopurinol on OPRT and ODC in erythrocytes of different density. The activity of OPRT, ODC, and APRT in erythrocytes of different density is illustrated in Fig. 3. APRT and ODC were assayed in cell fractions from eight healthy adults receiving no medications and six hyperuricemic patients treated with allopurinol at a dose of $300-400 \mathrm{mg} /$ day for 2 months to $6 \mathrm{yr}$. OPRT was assayed in cell fractions from four healthy adults receiving no drugs and five hyperuricemic patients receiving allopurinol as described above. All subjects had normal HGPRT.

There was no significant difference in the specific activity or rate of decline in activity of the APRT enzyme with increasing cell age in the control group as compared to the allopurinol-treated group $(P>0.05)$. ODC activity in fractionated erythrocytes from the control group decreased from $180 \%$ to $30 \%$ of mean activity with increasing cell density while ODC activity in fractionated erythrocytes from the allopurinol treated patients decreased from $160 \%$ to $54 \%$ of mean activity (A). ODC activity was significantly increased in each cell fraction from the allopurinol-treated group as compared with the corresponding cell fraction in the control group $(P=0.001)(B)$. Regression analyses by least squares showed no significant difference in the rate of decline of ODC activity from cells with increasing density $(P>0.05)$ between the treated and untreated patients. OPRT activity in the control group decreased from $217 \%$ to $24 \%$ of mean with increasing cell density and from $184 \%$ to $40 \%$ for the allopurinoltreated group (A). Again a significant increase in OPRT activity in the allopurinol therapy group was

TABLE III

The Effect of Prolonged Allopurinol Therapy on the Metabolism of Orotic Acid-7-14C In Vivo

\begin{tabular}{|c|c|c|c|c|c|c|c|c|}
\hline \multirow[b]{2}{*}{ Patient } & \multirow[b]{2}{*}{ Day } & \multirow[b]{2}{*}{ Allopurinol } & & & \multirow{2}{*}{\multicolumn{2}{|c|}{ Total urinary ${ }^{14} \mathrm{C}$-metabolites }} & \multicolumn{2}{|c|}{ Erythrocyte } \\
\hline & & & \multicolumn{2}{|c|}{${ }^{14} \mathrm{CO}_{2}$} & & & OPRT & ODC \\
\hline & & $m g / d a y$ & $d p m$ & \% control & $d p m \times 10^{-3}$ & $\%$ control & $n$ moles $/ m$ & olein/hr \\
\hline \multirow[t]{4}{*}{$\mathrm{AB}$} & 0 & None & 60,650 & 100 & 2553 & 100 & 0.110 & 0.120 \\
\hline & 8 & 800 & 47,246 & 77.9 & 5106 & 200 & 0.275 & 0.330 \\
\hline & 60 & 800 & 48,520 & 80 & 8125 & 318.3 & 1.540 & 1.500 \\
\hline & 67 & None for 7 days & 65.017 & 107.2 & 2131 & 83.5 & 1.340 & 1.227 \\
\hline \multirow[t]{4}{*}{ PS } & 0 & None & 61,725 & 100 & 1487 & 100 & 0.147 & 0.165 \\
\hline & 8 & 800 & 41,232 & 66.8 & 4928 & 331.3 & 0.200 & 0.302 \\
\hline & 60 & 800 & 47,466 & 76.9 & 3085 & 207.5 & 1.273 & 1.200 \\
\hline & 67 & None for 7 days & 81,909 & 132.7 & 1287 & 86.6 & 1.030 & 1.100 \\
\hline \multirow[t]{3}{*}{ JW } & $\mathbf{0}$ & None & 44,611 & 100 & 3041 & 100 & 0.190 & 0.157 \\
\hline & 8 & 800 & 40,179 & 89.7 & 6060 & 199.3 & 0.472 & 0.430 \\
\hline & 60 & 800 & 39.643 & 78.7 & 6260 & 205.8 & 0.960 & 1.320 \\
\hline
\end{tabular}



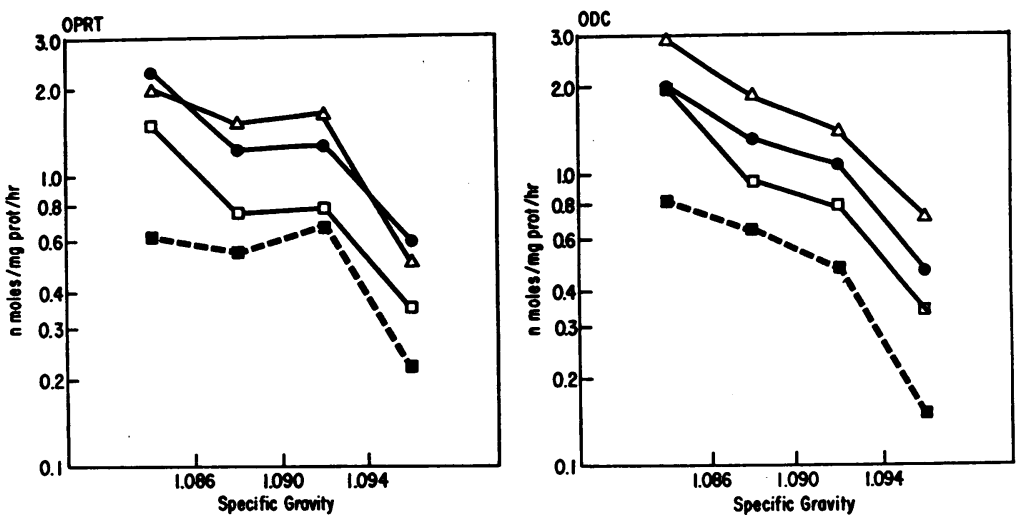

FIGURE 4 Orotate phosphoribosyltransferase (OPRT) and orotidylic decarboxylase (ODC) in circulating erythrocytes of different density after initiation of therapy with allopurinol $(800 \mathrm{mg} /$ day $)$ in patient C. R. Mean activity is plotted against specific gravity (increasing values correspond to

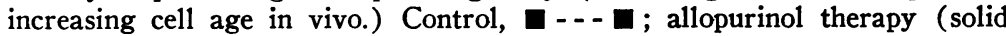
lines) ; day $6, \square \longrightarrow \square$; day 9 and $13, \square-\square$; day 16 and $20, \triangle \longrightarrow \triangle$.

maintained in all cell fractions $(P=0.016)(\mathrm{B})$. Regression analysis showed no difference in the rate of decline of OPRT activity between the control and allopurinol-treated groups. The difference in OPRT and ODC activity between control and allopurinoltreated groups was still evident if the curves were extended to a specific gravity of 1.062 , a value corresponding to the least dense cells in human blood (19).

The early effects of allopurinol therapy $(800 \mathrm{mg} /$ day) on OPRT and ODC activity in erythrocytes of increasing density is seen in Fig. 4 (patient C. R.). After only 6 days of therapy, there was increased ac- tivity of OPRT and ODC in all cell fractions. The activity of both enzymes continued to increase at approximately the same rate in cells of all ages with continued therapy. In a second patient treated with allopurinol (J. M.), an increase in OPRT activity was apparent in all cell fractions after 3 days of therapy. However, in J. M., in contrast to the results obtained in C. R., an increase in ODC activity was not observed during the first 16 days of therapy. This delayed increase in ODC activity is similar to that observed in A. H. (see Fig. 2). As illustrated in Fig. 5, the administration of oxipurinol $(800 \mathrm{mg} /$ day $)$ to W. H. H.

TABLE IV

The Effect of Prolonged Allopurinol Therapy on Urinary Excretion of Orotic Acid and Orotidine in Gouty Subjects

\begin{tabular}{|c|c|c|c|c|c|c|c|c|c|}
\hline & \multirow[b]{3}{*}{ Patient } & \multirow{3}{*}{$\begin{array}{c}\text { Treat- } \\
\text { ment } \\
\text { day }\end{array}$} & \multirow{3}{*}{$\begin{array}{c}\text { Serum } \\
\text { urate }\end{array}$} & \multicolumn{4}{|c|}{ Urinary } & \multirow{2}{*}{\multicolumn{2}{|c|}{ Erythrocyte }} \\
\hline & & & & \multirow{2}{*}{$\begin{array}{c}\text { Orotic } \\
\text { acid }\end{array}$} & \multirow[b]{2}{*}{ Orotidine } & \multirow{2}{*}{$\begin{array}{l}\text { Uric } \\
\text { acid }\end{array}$} & \multirow[b]{2}{*}{ Oxypurines } & & \\
\hline & & & & & & & & OPRT & ODC \\
\hline & & & $m g / 100 \mathrm{ml}$ & $m g / 24 h r$ & $m g / 24 \mathrm{hr}$ & $m g / 24 h r$ & umoles $/ 24 \mathrm{hr}$ & $n$ moles $/ m$ & protein/hr \\
\hline \multirow{6}{*}{$\begin{array}{l}\text { Normal } \\
\text { Gout } \\
\quad \text { R. R. }\end{array}$} & & & $3.0-7.0$ & $<2.0$ & $<2.0$ & $<600$ & $<50$ & $0.121 \pm 0.064$ & $0.128 \pm 0.068$ \\
\hline & Control & 0 & 9.2 & $<2.0$ & 6.9 & 898 & 481 & 0.179 & 0.164 \\
\hline & Allopurinol $(800 \mathrm{mg} /$ day $)$ & 3 & 10.0 & 8.6 & 37.8 & 506 & 879 & 0.246 & 0.222 \\
\hline & & 5 & 7.9 & - & 149.2 & 552 & 1612 & 0.270 & 0.249 \\
\hline & & 9 & 5.4 & 16.7 & 97.5 & 206 & 1965 & 0.376 & 0.300 \\
\hline & & 81 & 5.1 & 11.5 & 83.0 & 213 & 1281 & 1.120 & 1.176 \\
\hline \multirow[t]{5}{*}{ A. H.* } & Control & $\mathbf{0}$ & 9.7 & $<2.0$ & $<2.0$ & 512 & - & 0.030 & 0.082 \\
\hline & Allopurinol (400 mg/day) & 14 & 4.0 & 30.7 & 46.2 & 255 & 702 & 0.445 & 0.125 \\
\hline & & 32 & 6.9 & 13.4 & 35.5 & 144 & 1154 & 0.700 & 0.531 \\
\hline & & 70 & 6.2 & - & - & 24.3 & 554 & 0.990 & 0.526 \\
\hline & & 70 & 6.2 & - & - & 243 & 554 & 0.990 & 0.526 \\
\hline \multirow[t]{4}{*}{ J. E. J.* } & Control & 0 & 11.5 & - & - & 438 & 105 & 0.071 & 0.250 \\
\hline & Allopurinol (400 mg/day) & 14 & 6.2 & 11.3 & 112.4 & 361 & 1126 & 0.957 & 0.691 \\
\hline & & 56 & 8.0 & 11.2 & 83.4 & 261 & 456 & 1.571 & 1.120 \\
\hline & & 120 & 6.5 & 11.7 & 94.2 & - & 300 & 1.300 & 1.105 \\
\hline
\end{tabular}

* Urinary excretion based on mean excretion of $2500 \mathrm{mg}$ creatinine. 

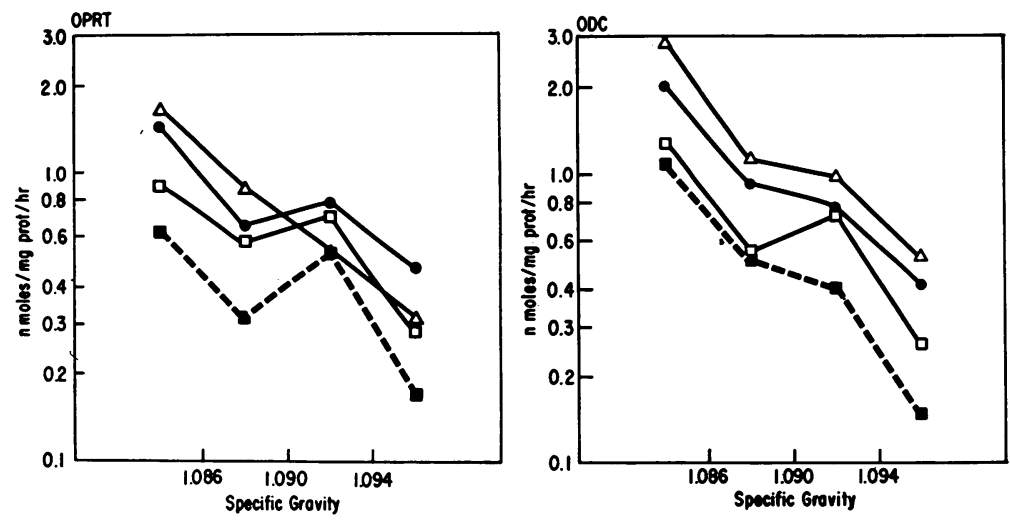

Figure 5 Orotate phosphoribosyltransferase (OPRT) and orotidylic decarboxylase (ODC) in circulating erythrocytes of different density after initiation of therapy with oxipurinol $(800 \mathrm{mg} /$ day $)$ in patient W. H. H. Mean activity is plotted against specific gravity (increasing values correspond to increasing cell age in vivo). Control, $\mathbf{0}-\mathbf{\square}_{\text {; }}$ allopurinol therapy (solid lines) ; day $3, \square-\square$; day $10, \bullet-\bullet$; day 13 and $17, \triangle-\triangle$.

led to an alteration of OPRT and ODC activity which was similar to that observed in C. R.

Effect of allopurinol and oxipurinol on OPRT activity in erythrocytes in vitro. Oxipurinol and to a lesser extent allopurinol were found to increase OPRT activity in vitro in erythrocytes obtained from patients not previously treated with allopurinol but not in erythrocytes from allopurinol-treated patients (Fig. 6). Incubation of erythrocytes from untreated patients for $4 \mathrm{hr}$ with oxipurinol at concentrations of $0.1 \mathrm{~mm}$ and $0.3 \mathrm{~mm}$, which are similar to those observed in plasma of allopurinol-treated patients, led to a $115 \%$ and $350 \%$ increase, respectively, in OPRT activity over control values. Incubation of the cells with $1 \mathrm{~mm}$ allopurinol for $4 \mathrm{hr}$ produced a $150 \%$ increase over control values. Control values remained essentially unchanged for the OPRT enzyme over the $4 \mathrm{hr}$ study period. The effect of oxipurinol and allopurinol was not altered when cycloheximide $(0.1 \mathrm{~mm})$ or actinomycin $\mathrm{D}(5 \mu \mathrm{g} / \mathrm{ml})$ were included in the incubation mixture. Oxipurinol and allopurinol at concentrations as high as $1 \mathrm{~mm}$ did not increase OPRT activity in erythrocytes from allopurinol-treated patients.

The increased enzyme activities produced by allopurinol or oxipurinol in vitro (or in vivo) were not altered by dialysis against $0.01 \mathrm{~m}$ Tris $\mathrm{HCl} \mathrm{pH} 7.40$ for $2 \mathrm{hr}$. In addition, no increase in OPRT activity could be demonstrated if the cells were lysed prior to incubation with either drug. The increase in OPRT activity produced by oxipurinol and allopurinol in vitro in intact cells from untreated patients was not associated with an increase in ODC activity. Incubation of intact erythrocytes in the presence of $1 \mathrm{~mm}$ orotic acid (two experiments) or $1 \mathrm{~mm}$ orotidine (one experiment)

TABLE V

Treatment of Hereditary Orotic Aciduria with Allopurinol

\begin{tabular}{|c|c|c|c|c|c|c|}
\hline & & \multirow[b]{2}{*}{ Treatment day } & \multicolumn{2}{|c|}{ Erythrocyte } & \multicolumn{2}{|c|}{ Urinary } \\
\hline & & & OPRT & ODC & Orotic acid & Orotidine \\
\hline & & & \multicolumn{2}{|c|}{$n$ moles $/ m g$ protein $/ h r$} & \multicolumn{2}{|c|}{$\mathrm{mg} / \mathrm{g}$ creatine } \\
\hline \multicolumn{7}{|c|}{ Orotic aciduria } \\
\hline TH & $\begin{array}{l}\text { Control } \\
\text { Allopurinol (100 mg/day) }\end{array}$ & $\begin{array}{r}0 \\
28 \\
56\end{array}$ & $\begin{array}{l}<0.001 \\
<0.001 \\
<0.001\end{array}$ & $\begin{array}{l}<0.001 \\
<0.001 \\
<0.001\end{array}$ & $\begin{array}{l}715.5 \\
611.6\end{array}$ & $\begin{array}{r}34.8 \\
150.0\end{array}$ \\
\hline $\mathrm{DB}$ & $\begin{array}{l}\text { Control } \\
\text { Allopurinol (100 mg/day) }\end{array}$ & $\begin{array}{r}0 \\
28 \\
56\end{array}$ & $\begin{array}{l}<0.001 \\
<0.001 \\
<0.001\end{array}$ & $\begin{array}{l}<0.001 \\
<0.001 \\
<0.001\end{array}$ & $\begin{array}{l}382.2 \\
414.0\end{array}$ & 134.0 \\
\hline
\end{tabular}

* Mean \pm SD. 


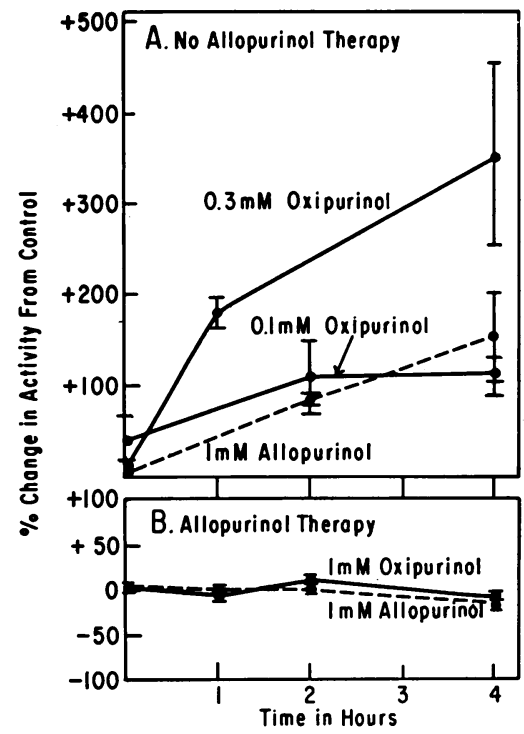

FIGURE 6 Effect of allopurinol and oxipurinol on OPRT activity in vitro in erythrocytes. (A) Untreated subjects. (B) Patients treated with allopurinol for $3 \mathrm{wk}$ to $6 \mathrm{yr}$. The values indicated represent the mean $\pm S D$ of $2-10$ different experiments expressed as per cent change from control OPRT activity observed in erythrocytes from the same patient incubated for the same length of time in the absence of drug. Control OPRT activity did not decrease during the incubation period. Allopurinol, -..-; Oxipurinol, -

produced no change in OPRT activity after $1-4 \mathrm{hr}$, respectively.

Effect of allopurinol on pyrimidine metabolism in patients with orotic aciduria. Two children with hereditary orotic aciduria $(21,22)$ were treated for 8 wk with allopurinol, 6-8 $\mathrm{mg} / \mathrm{kg}$ per day (Table V). Each patient was receiving exogenous uridine. During this period there was no change in erythrocyte OPRT or ODC activity. Urinary orotic acid similarly did not change. However, urinary orotidine increased from 34.8 and $21.3 \mathrm{mg} / \mathrm{g}$ creatinine to 150 and $134 \mathrm{mg}$, respectively, for patients T. H. and D. B.

\section{DISCUSSION}

Shuster (23) and Goldstein and Goldstein (24) have proposed a molecular model to explain drug effect, tolerance, and withdrawal in which drug-mediated inhibition of an enzyme is followed by increased levels of the inhibited enzyme. This increase in enzyme activity would result in the need for larger amounts of drug to effect the same response. Similarly abrupt withdrawal of the drug would result in a temporary excess in product formation due to the uninhibited increase in enzyme activity. This model is quite general and increased enzyme activity could be due to increased enzyme protein as a result of an alteration in the rate of enzyme synthesis or degradation or due to an activation of the enzyme molecule. Pinsky and Krooth found an increase in the levels of the OPRT and ODC in cultured fibroblasts following the addition of azauridine which, upon conversion to its ribonucleotide derivative, is a potent inhibitor of $\operatorname{ODC}(25,26)$. In addition, the administration of 6-azauridine to rats for 10 days results in greater than a two-fold increase in ODC activity in spleen, liver, kidney, and heart (27). Krooth has recently emphasized the relevance of these observations in cell culture and in experimental animals to this proposed model of drug tolerance (27). Fallon, Frei, and Freireich described the development of "clinical resistance" to 6-azauridine therapy in patients with leukemia when in spite of an increased dose of 6azauridine there was a decrease in the amount of measured inhibition of orotidylic decarboxylase and no fall in the white blood cell count (28).

The finding in man that allopurinol mediated inhibition of pyrimidine biosynthesis de novo is followed by an increased activity of erythrocyte OPRT and ODC, the two enzymes which are thought to be inhibited, would also appear to be consistent with this model of drug tolerance. The observed increase in ODC in leukocytes adds further support for this thesis suggesting that the response is manifest in nucleated as well as non-nucleated cells. However, attempts to determine if the increased activity of OPRT and ODC during allopurinol therapy reflected the development of tolerance to the inhibitory effect of allopurinol on pyrimidine biosynthesis were largely unsuccessful. First, the allopurinol-mediated inhibition of orotic acid- $7{ }^{14} \mathrm{C}$ metabolism remains essentially unchanged during prolonged therapy. However, interpretation of this finding is difficult since the blood and tissue levels of the actual inhibitors of pyrimidine biosynthesis as well as orotic acid itself are unknown. In addition, although there was no discernible decrease in urinary orotic acid or orotidine with extended treatment the values observed were quite variable. Nonetheless, the alteration of OPRT and ODC activity observed during allopurinol and oxipurinol therapy appears to represent a rather unique example in man where the mechanism of drug-mediated increase in enzyme activity can be examined directly.

Increased enzyme activity could theoretically be due to enzyme stabilization, induction of enzyme synthesis, or enzyme activation. Fox, Wood, and O'Sullivan have attributed this increase in activity to "pseudo-substrate" stabilization of the OPRT and ODC enzymes (29). In our studies enzyme stabilization does not seem to account for the increased erythrocyte OPRT and ODC activity resulting from allopurinol therapy since there is no significant difference in the rate of decline of enzyme activity with cell aging between the control 
and allopurinol-treated groups and a comparable increase of activity was observed in all cell fractions. In addition, the increase in OPRT and ODC activity was evident to approximately the same degree in all cell fractions after the initiation of therapy with either allopurinol or oxipurinol. This observation is inconsistent with enzyme stabilization in which one would expect a relative increase in activity of the older cell fractions with little or no change in activity of the younger fractions. In addition, this finding is not consistent with the hypothesis that induction of enzyme synthesis in nucleated erythropoietic precursors is the major factor responsible for the increased activity observed. In this case, one would expect to see a striking increase in the activity of the youngest cell fractions with no change in activity in the older cell fractions. Thus, by exclusion, it appeared that the increased activity was due, at least in part, to enzyme activation. The observation that the increase in OPRT activity precedes the increase in ODC activity suggests that the primary effect of allopurinol and oxipurinol may be on the OPRT enzyme.

An increase in OPRT activity was demonstrated by incubation of intact erythrocytes from untreated patients with allopurinol or oxipurinol in vitro. Several observations indicated that this effect observed in vitro was also due to "activation" of the enzyme. First, the increased activity could not be attributed to increased protein synthesis due to an alteration in the rate of translation or transcription since mature human erythrocytes cannot perform these cellular functions and the effect was not altered by inhibitors of these processes. Secondly, stabilization of the enzyme in vitro could not account for the absolute increase in activity observed. The observation that no increase in activity occurred when cells from allopurinol-treated patients were incubated with allopurinol or oxipurinol provided further evidence that the effect observed in vitro was similar to that observed in vivo. Despite the apparent similarity of the "activation" of OPRT observed in vitro as compared with that observed in vivo, several important differences were noted which cannot readily be accounted for. The rate of increase in erythrocyte OPRT activity was much greater in vitro than in vivo. This could be a reflection of the time necessary after the administration of allopurinol or oxipurinol in vivo to achieve a concentration of oxipurinol in plasma comparable with that used in vitro. However, we have no data relevant to this hypothesis. In addition, in contrast to the findings in vivo, there was no increase in the activity of ODC after incubation of erythrocytes with oxipurinol or allopurinol in vitro. Since the increase in OPRT activity usually preceded the increase in ODC activity in vivo, perhaps a similar delay would have been observed in vitro if incubation conditions could have been further prolonged.

The exact mechanism responsible for this apparent "activation" of OPRT by allopurinol and oxipurinol in vitro is not clear. It certainly differs from enzyme activation in the classical sense in that it appears to require the presence of an intact cell and removal of low molecular weight components by dialysis does not reverse the effect. A similar enzyme "activation" occurring only in intact cells has been reported by Comstock and Udenfriend with collagen proline hydroxylase in response to lactate in fibroblasts (30).

Previous studies of OPRT and ODC from mammalian sources have shown that these two enzymes copurify up to 5400 -fold and are not separated by classical methods (31-33). In addition, patients with hereditary orotic aciduria with one possible exception (34) exhibit a deficiency of both of these enzymes (35). These previous observations suggest that the two enzyme activities reside in the same enzyme protein or that the two enzymes are related in a complex. The findings reported here are consistent with either hypothesis. However, in contrast to the findings reported by Fox, Wood, and O'Sullivan (29), the level of OPRT activity in erythrocytes was not always the same as the level of ODC activity. This was particularly true when activity of the two enzymes in erythrocytes is compared within a few days after initiation of allopurinol therapy. Fox, Wood, and O'Sullivan apparently did not examine the level of activity of both enzymes during the period when enzyme activity was rapidly increased. This could account for the differences in our findings.

The increased OPRT and ODC activity produced by allopurinol administration in man suggested an alternate approach to therapy of patients with orotic aciduria who have a deficiency of both of these enzymes in vivo. Two children with hereditary orotic aciduria were treated with allopurinol for up to $8 \mathrm{wk}$. During this treatment period, no increase in OPRT or ODC activity was observed in circulating erythrocytes. In addition, there was no detectable decrease in urinary orotic acid excretion. However, the presence of orotidine in the urine as well as the increase in urinary orotidine during the treatment with allopurinol suggests that both patients had some OPRT activity in vivo.

\section{ACKNOWLEDGMENTS}

We wish to thank Mrs. Frances Benezra, Mrs. Margaret C. Evans, and Mrs. Jean C. Meade for their technical assistance; Mr. Roy Nance and Dr. J. A. Kylstra, Duke University Pulmonary Laboratory, for assistance in collection of respiratory gases; Dr. F. S. Porter, Duke University, and Dr. R. Heyn, The University of Michigan, for collaboration and treatment of their patients with hereditary orotic acid- 
uria; Dr. H. K. Thompson, Jr., and Dr. C. F. Starmer for assistance with statistical analysis of the data.

This investigation was supported by U. S. Public Health Service Grants AM12413, AM14362, and AM04620; and supported in part by a grant (RR-30) from the General Clinical Research Centers Program of the Division of Research Resources, National Institutes of Health.

\section{REFERENCES}

1. Rundles, R. W., E. N. Metz and H. R. Silberman. 1966. Allopurinol in the treatment of gout. Ann. Intern. Med. 64: 229.

2. Feigelson, P., J. D. Davidson, J. D., and R. K. Robins. 1957. Pyrazolopyrimidines as inhibitors and substrates of xanthine oxidase. J. Biol. Chem. 226: 993.

3. Elion, G. B., T. F. Yu, A. B. Gutman, and G. H. Hitchings. 1968. Renal clearance of oxipurinol, the chief metabolite of allopurinol. Amer. J. Med. 45: 69.

4. Fox, R. M., D. Royse-Smith, and W. J. O'Sullivan. 1970. Orotidinuria induced by allopurinol. Science (Washington). 168: 861.

5. Kelley, W. N., and T. D. Beardmore. 1970. Allopurinol: alteration in pyrimidine metabolism in man. Science (Washington). 169: 388.

6. Beardmore T. D., and W. N. Kelley. 1971. Studies on the mechanism of allopurinol-induced inhibition of pyrimidine metabolism. Clin. Res. $19: 27$.

7. Kelley, W. N., T. D. Beardmore, I. H. Fox, and J. C. Meade. 1971. Effect of allopurinol and oxipurinol on pyrimidine synthesis in cultured human fibroblasts. Biochem. Pharmacol. 20: 1471.

8. Kasbekar, D., A. Nagabhushanam, and D. M. Greenberg. 1964. Purification and properties of orotic aciddecarboxylating enzymes from calf thymus. J. Biol. Chem. 239: 4245.

9. Kelley, W. N., F. M. Rosenbloom, J. F. Henderson, and J. E. Seegmiller. 1967. A specific enzyme defect in gout associated with overproduction of uric acid. Proc. Nat. Acad. Sci. U. S. A. 57: 1735.

10. Lowry, O. H., N. J. Rosenbrough, A. L. Farr, and R. J. Randall. 1951. Protein measurement with the Folin phenol reagent. J. Biol. Chem. 193: 265.

11. Liddle, L. J. E. Seegmiller, and L. Laster. 1959. The enzymatic spectrophotometric method for determination of uric acid. J. Lab. Clin. Med. 54: 903.

12. Klinenberg, J. R., S. Goldfinger, K. H. Bradley, and J. E. Seegmiller. 1967. An enzymatic spectrophotometric method for the determination of xanthine and hypoxanthine. Clin. Chem. 13: 834.

13. Scott, C. D. 1968. Analysis of urine for its ultraviolet absorbing constituents by high-pressure, high-resolution anion exchange chromatography. Clin. Chem. 14: 521 .

14. Rabkin, M. T., E. W. Frederick, M. Lotz, and L. H. Smith, Jr. 1962. Pyrimidine metabolism in man V. The measurement in vivo of the biochemical effect of antineoplastic agents in animals and human subjects. $J$. Clin. Invest. $41: 871$.

15. Baggliolini, M., and M. H. Bickel. 1966. A new type of incubation apparatus for the determination of metabolically produced ${ }^{14} \mathrm{CO}_{2}$. Anal Biochem. 14: 290.

16. Chodirker, W. B., G. N. Bock, and J. H. Vaughan. 1968. Isolation of human PMN leukocytes and granules: observations on early blood dilution and on heparin. J. Lab. Clin. Med. 71:9.

17. Baehner, R. L. and D. G. Nathan. 1968. Quantitative nitroblue tetrazolium test in chronic granulomatous disease. N. Engl. J. Med. 278: 971.

18. Brok, F., B. Ramot, E. Zwang, and D. Danon, 1966. Enzyme activities in human red blood cells of different age groups. Israel Med. J. 2: 291.

19. Danon, D., and Y. Marikousky. 1964. Determinations of density distribution of red cell population. J. Lab. Clin. Med. $64: 668$.

20. Starmer, C. F., and J. E. Grizzle. 1968. A computer program for analysis of data by general linear models. Chapel Hill, University of North Carolina (Institute of Statistics Mimeo Series No. 560).

21. Tubergen, D. G., R. S. Krooth and R. M. Heyn. 1969. Hereditary orotic aciduria with normal growth and development. Amer. J. Dis. Child. 118: 864.

22. Rogers, L. E., L. R. Warford, R. B. Patterson, and F. S. Porter. 1968. Hereditary orotic aciduria. A new case with family studies. Pediatrics. 42: 415.

23. Shuster, L. 1961. Repression and de-repression of enzyme synthesis as a possible explanation of some aspects of drug action. Nature (London). 189: 314.

24. Goldstein, A., D. B. Goldstein. 1968. Enzyme expansion theory of drug tolerance and physical dependence. Res. Publ. Assoc. Res. Nerve. Ment. Dis. 46: 265.

25. Pinsky, L., and R. S. Krooth. 1967. Studies on the genetic control of pyrimidine biosynthesis in human diploid cell strains. I. Effect of 6-azauridine on cellular phenotype. Proc. Nat. Acad. Sci. U. S. A. 57: 925.

26. Pinsky, L., and R. S. Krooth. 1967. Studies on the control of pyrimidine biosynthesis in human diploid cell strains. II. Effects of 5-azaorotic acid, barbituric acid and pyrimidine precursors on cellular phenotype. Proc. Nat. Acad. Sci. U. S. A. 57: 1267.

27. Krooth, R. S. 1971. Molecular models for pharmacological tolerance and addiction. Ann. N. Y. Acad. Sci. 179: 548 .

28. Fallon, H. J., E. Frei and E. Freireich. 1962. Correlation of the biochemical and clinical effects of 6-azauridine in patients with leukemia. Amer. J. Med. 33: 526.

29. Fox, R. M., M. H. Wood, and W. J. O'Sullivan. 1971. Studies on the coordinate activity and lability of orotidylate phosphoribosyltransferase and decarboxylase in human erythrocytes, and the effects of allopurinol administration. J. Clin. Invest. 50: 1050.

30. Comstock, J. P., and S. Udenfriend. 1970. Effect of lactate on collagen proline hydroxylase activity in cultured L-929 fibroblasts. Proc. Nat. Acad. Sci. U. S. A. $66: 552$.

31. Hatfield, D., and J. B. Wyngaarden. 1964. 3-ribosylpurines. I. Synthesis of (3-ribosyluric acid) 5'-phosphate and (3-ribosylxanthine) $5^{\prime}$-phosphate by a pyrimidine ribonucleotide pyrophosphorylase of beef erythrocytes. J. Biol. Chem. 239: 2580.

32. Appel, S. H. 1968. Purification and kinetic properties of brain orotidine-5'-phosphate decarboxylase. J. Biol. Chem. 243: 3924.

33. Kaskebar, D. K., A. Nagabhushanam, D. M. Greenberg. 1964. Purification and properties of orotic aciddecarboxylating enzymes from calf thymus. J. Biol. Chem. 239: 4245.

34. Fox, R. M., W. J. O'Sullivan, and B. G. Firken. 1969. Orotic aciduria differing enzyme patterns. Amer. $J$. Med. $47: 332$.

35. Smith, L. H., Jr., M. Sullivan, and C. M. Huguley, Jr. 1961. Pyrimidine metabolism in man. IV. The enzymatic defect of orotic aciduria. J. Clin. Invest. 40: 656. 